Res Publica. Revista de Historia de las Ideas Políticas ISSN: 1576-4184

http://dx.doi.org/10.5209/RPUB.60849

\title{
Los fundamentos del conservadurismo en Estados Unidos: del congregacionalismo puritano al republicanismo cívico
}

\author{
Pedro Francisco Ramos Josa*
}

Recibido: 21 de enero de 2018 / Aceptado: 15 de junio de 2018

Resumen. El presente trabajo tiene por objeto dilucidar las raíces del conservadurismo en Estados Unidos. Para ello resulta imprescindible realizar un análisis del republicanismo calvinista de las primeras colonias de Nueva Inglaterra, indicando sus elementos constitutivos y los motivos que le impidieron ofrecer a los revolucionarios la legitimación teórica que sí les proporcionó el republicanismo clásico. La influencia del republicanismo fue facilitada por la cantidad de similitudes que compartía con el puritanismo. De ahí que dicha transición se efectuase de forma paulatina, sin rupturas traumáticas, dando como resultado una constante evolución que condujo inicialmente a la revolución contra el Imperio Británico, y a la creación de un nuevo orden republicano después.

Palabras clave: republicanismo calvinista; constitucionalismo; congregacionalismo; republicanismo clásico; revolución.

\section{[en] The Foundations of Conservatism in United States of America: from the Puritan Congregationalism to the Civic Republicanism}

\begin{abstract}
The aim of the present article is to elucidate the foundations of the conservatism in United States of America. To that end, it is essential to make an analysis of the Calvinist republicanism in the early colonies of New England, denoting its constituent elements and the causes that prevented it from offering the revolutionaries the theoretical legitimation that the classic republicanism was able to provide them. The influence of republicanism was supported by the amount of similarities that shared with puritanism. Hence, that transition was completed gradually, without disturbing ruptures, resulting in a relentless evolution that initially led to the revolution against the British Empire, and then to the formation of a new republican order.

Keywords: Calvinist Republicanism; Constitutionalism; Congregationalism; Classic Republicanism; Revolution.
\end{abstract}

Sumario: 1. Periodo colonial: el puritanismo. 1.1. Las colonias del pacto. 1.2. Ordenamiento interno de las colonias. 1.3. Causas del declive puritano. 2. Periodo revolucionario y constitucional: Similitudes entre puritanismo y republicanismo clásico. 3. Incidencia del puritanismo y republicanismo en el conservadurismo de Estados Unidos

Cómo citar: Ramos Josa, P.F. (2018). Los fundamentos del conservadurismo en Estados Unidos: del congregacionalismo puritano al republicanismo cívico, en Res publica 21.2, 253-269.

\footnotetext{
* Universidad Europea Miguel de Cervantes pedrofrjosa@gmail.com
} 
Si discernir la historia de toda revolución es un ejercicio de extremada complejidad, en el caso estadounidense nos encontramos ante la paradoja de una revolución conservadora, cuyo éxito no hizo más que resaltar las contradicciones internas derivadas de semejante oxímoron. En dicha armonía de los opuestos, la transformación del rigorismo puritano en fervor revolucionario se nos presenta menos sorprendente si tenemos en cuenta los numerosos nexos de unión entre congregacionalismo protestante y republicanismo clásico, lo que propició una evolución ideológica sin grandes rupturas conceptuales. Es más, merced a dicha compatibilidad de principios, el puritanismo continuó influyendo en el devenir político estadounidense pese al dominio ejercido por el republicanismo, influencia que, como veremos, acentuó los elementos más conservadores propios de ambas visiones.

Pese a no ser el grupo más numeroso ni popular entre los protestantes, "les calvinistes n'en ont pas moins exercé une influence énorme sur l'évolution de la politique, des universités et de la conscience nationale américaines" ${ }^{1}$, de hecho, como señala Steinmetz, "no one can claim to understand American history and culture without some appreciation of its Calvinist heritage"2.

\section{Periodo colonial: el puritanismo}

\subsection{Las colonias del pacto}

Los primeros colonos que llegaron a Nueva Inglaterra no lo hicieron en un vacío ideológico, pues tenían en mente el modelo de sociedad que implantarían en sus colonias, desde el ámbito religioso al económico y político, no en vano:

les puritains avaient pour objectif la réforme complète non seulement de l'Eglise mais aussi de l'Etat et de la société, ils voulaient établir une "communauté biblique" fondée sur un contrat social passée entre gens qui étaient un même temps coreligionnaires et concitoyens ${ }^{3}$.

Sin un control exhaustivo ni una única forma legal de lazo con Londres, hasta 1650 hubo cuatro tipos de estructuras coloniales, a saber: las provincias reales, las ocupaciones de las compañías comerciales, las propiedades concedidas a individuos y las comunidades fundadas por un pacto.

Este último tipo, las colonias basadas en un pacto, fueron fundadas sin ninguna sanción real, ni legal ni constitucional, tomando la iniciativa los mismos colonos a la hora de organizar internamente sus comunidades, creando de ese modo sus propias

J. D. Bratt, "Le calvinisme en Ámerique du Nord", en M. E. Hirzel y M. Sallmann (ed.), Calvin et le calvinisme, Genève, Labor et Fides, 2008, p. 8.

2 D. Steinmetz, Calvin in Context, Oxford, Oxford University Press, 1995, p. 5.

3 J. D. Bratt, op. cit., p. 88. De hecho, y como resultado de la falta de un plan definido de colonización por parte de la Corona Británica, las señas de identidad de las primeras colonias británicas en Norteamérica fueron la libertad religiosa y las reuniones democráticas, es más, la existencia de colonias precedió al establecimiento del Imperio Británico, C. Ubbelohde, The American Colonies and the British Empire, 1607-1763, London, Routledge, 1968, pp. 1-14. 
estructuras políticas ${ }^{4}$. Tal circunstancia se debió a que la cuestión de la libertad de culto fue una de las principales causas de la emigración a América, junto con las oportunidades económicas que ofrecía y la relajación de ciertas rigideces sociales respecto a Gran Bretaña (aristocracia, impuestos, yugo religioso, etc.) . $^{5}$

Si la primera colonia exitosa fue la de Jamestown, Virginia, en 1607, los puritanos establecieron en Plymouth su primera comunidad en 1621, absorbida finalmente por Massachusetts, creada en 1630 por puritanos reformistas rigoristas que ansiaban una versión más calvinista de la sociedad que la vivida en Gran Bretaña. Aunque el resto de colonias establecidas en Nueva Inglaterra fueron mucho más tolerantes que Massachusetts, todas ellas tuvieron en común en sus inicios una gran preocupación por las cuestiones religiosas, al menos en mayor grado que en Chesapeake o el Caribe, áreas mucho más materialistas e individualistas ${ }^{6}$. Como señala Bainton, Calvino moldeó Ginebra y Escocia, dividió a Holanda y Francia, y guió a Nueva Inglaterra ${ }^{7}$. El que los congregacionalistas escogiesen Plymouth no fue fruto de la casualidad, sino un proyecto ansiado desde 1593, cuando los puritanos huidos a Leyden, Holanda, pidieron a la Corona Británica permiso para asentarse en Norteamérica. El motivo principal de su emigración había sido su discrepancia con los elementos papistas que percibían en la Iglesia oficial, como su estrecha relación con el Estado, su jerarquía eclesiástica y ciertas formas de idolatría, además de estar abierta a todos, en lugar de reservada a los santos visibles, manteniendo así la creencia en la predestinación de Calvino. La patente para poder establecerse en Norteamérica fue finalmente concedida en 1620, y los puritanos contactaron con el comerciante Thomas Weston para que costease el viaje a cambio de los beneficios de siete años. De ese modo viajaron en el Mayflower 101 personas, 87 puritanos reformistas más los trabajadores que Weston había contratado para poner en marcha la colonia ${ }^{8}$.

Durante la travesía, el 11 de noviembre de 1620, conocedores de los problemas que habían sufrido similares empresas en Virginia y las Bermudas, 41 hombres, incluidos miembros de la tripulación, suscribieron un contrato ante la inexistencia de una carta que sirviese de modelo a su proyecto. Por el mismo acordaron

covenant and combine our selves together into a civil body politic, for our better ordering and preservation and furtherance of the ends aforesaid; and by virtue hereof to enact, constitute, and frame such just and equal laws, ordinances, acts, constitutions and offices, from time to time, as shall be thought most meet and convenient for the general good of the Colony, unto which we promise all due submission and obedience ${ }^{9}$.

En conformidad con dicho acuerdo, a su llegada a Plymouth, todos los hombres libres votaron y eligieron a William Bradford como su gobernador por los siguientes

\footnotetext{
Ibidem, p. 15.

5 De ese modo, mientras Nueva Inglaterra fue colonizada por puritanos desafectos o perseguidos en Inglaterra, Pennsylvania fue fundada por William Penn como un refugio para los cuákeros, aunque pronto se convirtió en un bastión de tolerancia, mientras Maryland se concibió como nuevo cobijo para los católicos, idea ya contemplada por Sir Humphrey Gilbert desde 1582, S. Sarson, British America 1500-1800. Creating Colonies. Imagining an Empire, New York, Bloomsbury, 2005, p. 31.

Ibidem, p. 120.

R. H. Bainton, The Travail of Religious Liberty, Philadelphia, The Westminster Press, 1951, p. 54.

S. Sarson, op. cit., p. 123.

Pacto del Mayflower, 1620, recuperado de Internet (http://www.pilgrimhallmuseum.org/mayflower_compact_ text.htm).
} 
30 años, en los cuales, pese a las dificultades económicas, la colonia creció hasta los 1.300 habitantes ${ }^{10}$. De todos modos, pronto el rigorismo religioso de los puritanos produjo las primeras desavenencias. Así, en 1635, el predicador Roger Williams fue expulsado de Massachusetts por repudiar los fundamentos de la teocracia, al defender la separación entre Iglesia y Estado, pues temía que de continuar unidos, la primera, reservada a los regenerados, sería corrompida por el segundo, que incluía a los no creyentes. De hecho, Williams abogaba por una secularización del Estado, extendiendo la democracia congregacionalista del calvinismo a la esfera política, justo lo contrario a lo que ocurría en Massachusetts, donde una décima parte, los creyentes, dominaban al 90 por cien de la población restante, que al no ser verdaderos fieles no disfrutaban de derecho a voto ${ }^{11}$. De ese modo, la separación de la Iglesia del Estado iba unida en Williams a la democratización política, pues sin la primera la segunda era impracticable, y sin ambas no podría existir libertad religiosa alguna.

Al fundar la plantación de Providence en 1644 como refugio ante la intolerancia puritana, Roger Williams abrió el camino para que Rhode Island se erigiera en una nueva colonia donde escapar del autoritarismo religioso de los primeros peregrinos. Las Actas y Órdenes por él diseñadas en 1647 otorgaban a los colonos un gobernador y una legislatura electas, con un amplio sufragio, además del reconocimiento de la libertad de conciencia ${ }^{12}$. En 1663, Rhode Island logró de Carlos II una nueva patente que certificaba su condición de colonia. Un año antes, fue Connecticut la que había recibido una Carta Real por la que se reconocía a la nueva colonia, en parte gracias a que John Winthrop Jr. supo presentar a su tierra como un contrapeso moderado a la dogmática Massachusetts, que por entonces continuaba sin reconocer la restauración monárquica ${ }^{13}$. De todos modos, Connecticut se había dotado ya en 1639 de unas Órdenes Fundamentales que recogían su condición de colonia independiente, en lo que constituye para muchos el primer ejemplo de constitución escrita moderna.

\subsection{Ordenamiento interno de las colonias}

No es extraño, por tanto, que para Osgood, los puritanos de Nueva Inglaterra fuesen los únicos colonos políticamente autoconscientes, al llevar consigo el derecho común y el gobierno local de sus anteriores establecimientos, manteniendo así su sistema de creencias en el nuevo mundo ${ }^{14}$. Si bien no tenían la intención de crear un Estado democrático, como atestiguan los requisitos confesionales que los puritanos exigían para la obtención de la ciudadanía, sí es cierto que al implantar en la esfera civil el sistema electivo imperante en el gobierno eclesiástico, introdujeron el espíritu democrático en sus colonias ${ }^{15}$. En la constitución de las mismas, los puritanos siguieron el modelo de Iglesia diseñado por Calvino, cuya estructura de gobierno consistía en el pastor a cargo de cada Iglesia, el cual debía presidirla de forma digna, instruir al pueblo en la doctrina cristiana, administrar los sacramentos y corregir las

\footnotetext{
S. Sarson, op. cit., p. 125.

R. H. Bainton, op. cit., p. 224.

S. Sarson, op. cit., p. 134.

Ibidem, p. 133.

H. L. Osgood, "The Political Ideas of the Puritans”, en Political Science Quarterly 6, 1891, pp. 1-28, aquí p. 1.

Ibidem, p. 16.
} 
faltas manteniendo la disciplina adecuada, pero que "non debet ipse de migratione cogitare, nec prout sibi commodum putarit ${ }^{\prime \prime 16}$.

De ahí la importancia que tenía la elección de un buen pastor, pues no todos podían serlo, para ello se requería tener vocación y saber responder adecuadamente a ella, no en vano, "non esse eligendos nisi qui sint sanae doctrinae et sanctae vitae, nec aliquo vitio notabiles...hoc est, ut instructi sint iis facultatibus quae ad implendum suum munus erunt necessariae" ${ }^{17}$. Y Calvino habló de ser elegidos pues "ostendunt sacerdotis ordenationem non sibi sub populi assistentis conscientia fieri oportere; ut sit ordinatio iusta et légitima, quae ominium testimonio fuerit examinata" ${ }^{18}$. Eso sí, aunque para Calvino las personas idóneas debían ser elegidas con el consentimiento y aprobación del pueblo, asimismo introducía un elemento de control, ya que "praeesse autem electioni debere alios pastores, ne quid per levitatem, vel per mala studia, vel per tumultum a multitudine peccetur"19.

El carácter electivo de los pastores mediante la participación del pueblo no era una novedad creada por Calvino, sino que suponía un regreso a las prácticas de la Iglesia primitiva ${ }^{20}$. De todos modos, para evitar los alborotos derivados de intentar poner de acuerdo a tanta gente, la elección correspondía primeramente al clero, quien tras someter a un duro examen al candidato, planteaba su ratificación a la voluntad popular. Lo esencial era "quam ne ab inconsiderata multitudine patiantur se abripi clerici et primores; sed potius sua prudentia et gravitate stultas eius cupiditates, si quando opus fuerit, reprimant" ${ }^{21}$. Pero dicho sistema fue corrompido por la tiranía del Papado, primero eligiendo a hombres indignos para sus cargos, y segundo, "Iam in eligendo totum illud ius populi sublatum est...Ad solos canonicos integra potestas translata est. Illi in quem volunt, conferunt episcopatum" "22, pues entendieron que el pueblo había renunciado a usar el buen juicio en sus elecciones, dejándose llevar únicamente por sus afectos. Tal usurpación era contraria a la palabra de Dios, al ser un "iure divino testatur ne fiat nisi ex consensu populi" ${ }^{23}$, dando como resultado que "nullo ex ordine (el eclesiástico) aptiores aut peritiores omnis imposturae, fraudis, proditionis, perfidiae magistri; nusquam tantum ad nocendum vel solertiae, vel audaciae"24.

Obediencia a la palabra de Dios, recuperación de la tradición, participación del pueblo y alejamiento de la corrupción católica, tales eran, por tanto, las principales señas de identidad del modelo de Iglesia propuesto por Calvino. Por consiguiente, no resulta extraño que en las primeras colonias la libertad estuviese basada en la autoridad, con un claro predominio del elemento aristocrático (ministros y magistrados) sobre el democrático (congregación), pues ambas esferas, religiosa-interna y civil-externa, debían estar guiadas por la palabra de Dios, donde el pacto era el origen de toda relación ${ }^{25}$.

\footnotetext{
J. Calvino, Institutionis religionis christianae editio ultima, Joannis Calvini opera quae supersunt omnia, Tomo II, Brunsvigae, C.A. Schwetschke, 1863, p. 403.

Ibidem, p. 404.

Ibidem, p. 405.

Ibidem.

Ibidem, p. 410.

Ibidem

Ibidem, p. 412

Ibidem.

Ibidem, p. 416.

H. L. Osgood, op. cit., p. 24.
} 
Como indica Posada, la democracia religiosa puritana independiente de los colonos de Norteamérica se trasladó al plano político, adelantándose incluso al Agreement of the Peolple redactado en 1647 por los Levellers del ejército de Cromwell, quienes llevaron a la práctica la idea de "un documento solemne donde se señalase los límites de la autoridad y la garantía de los derechos del pueblo"26, incluyendo el control al Parlamento limitando su poder, la libertad de conciencia y el reconocimiento de ciertos derechos innatos ${ }^{27}$. Pero mientras en Inglaterra dicho contrato social fue rechazado por el consejo general del ejército de Cromwell, en las colonias de Nueva Inglaterra los pactos de establecimiento se convirtieron en la fuente de su ordenamiento civil. Así, tras el pacto del Mayflower, en 1636 se aprobó en Plymouth el Código de Ley Peregrino, por el que

we think good that it be established for an act that, according to the ... and due privileges of the subject aforesaid, no imposition, law, or ordinance be made or imposed upon us by ourselves or others at present or to come but such as shall be made or imposed upon us by consent of the Body of Freemen or Associates, or their Representatives legally assembled ${ }^{28}$.

Poco después, en 1639, los huidos de Massachusetts acordaron sus Órdenes Fundamentales, inspiradas en los sermones de Thomas Hooker y en el modelo existente en Massachusetts, y según las cuales se establecía

an orderly and decent Government established according to God, to order and dispose of the affairs of the people at all seasons as occasion shall require; do therefore associate and conjoin ourselves to be as one Public State or Commonwealth [...] enter into Combination and Confederation together, to maintain and preserve the liberty and purity of the Gospel of our Lord Jesus which we now profess, as also, the discipline of the Churches, [...] as also in our civil affairs to be guided and governed according to such Laws, Rules, Orders and Decrees as shall be made, ordered, and decreed ${ }^{29}$.

De ese modo se seguía al pie de la letra el Plan de Tratado diseñado por Calvino, que constaba de un magistrado que debía ser el guardián y conservador de las leyes, de unas leyes conforme a las cuales el primero debía gobernar y de un pueblo gobernado por estas y que debe obediencia a aquel, ya que su poder proviene de Dios ${ }^{30}$. A Connecticut le siguió pronto New Haven con sus Artículos Fundamentales de ese mismo año 1639, y más tarde Rhode Island en 1647. Por tanto, al haber sido la preocupación religiosa por vivir conforme a los preceptos calvinistas el principal motor de la democratización política en Nueva Inglaterra, Jellinek no dudó en afirmar que

26 A. Posada, "Estudio preliminar", en J. Amuchastegui (ed.), Orígenes de la Declaración de Derechos del Hombre y del Ciudadano, Madrid, Editorial Nacional, 1984, pp. 225-261, aquí en p. 243.

27 G. Jellinek, "La Declaración de los Derechos del Hombre y del Ciudadano", en J. Amuchastegui (ed.), op. cit., pp. 57-121, aquí en p. 99.

28 Pilgrim Code of Law, 15 de noviembre de 1636, recuperado de Internet (http://teachingamericanhistory.org/ library/document/pilgrim-code-of-law/).

29 Fundamental Orders of 1639, recuperado de Internet (http://avalon.law.yale.edu/17th_century/order.asp).

30 J. Calvino, op. cit., p. 560. 
el origen de la consagración legislativa de los derechos naturales no era política, sino religiosa, y más en concreto, fruto de la Reforma ${ }^{31}$.

Esa sería la mayor aportación del puritanismo al modelo político estadounidense, al haber trasplantado a la esfera civil su congregacionalismo religioso primero, y al haber sancionado después la libertad religiosa y la separación Iglesia-Estado, convirtió en universales unos principios democráticos que en principio solo se aplicaban a los verdaderos creyentes. Desde luego, los puritanos no tenían en mente erigir una democracia en sus colonias, pero sin duda que sus pactos de establecimiento instituyeron los primeros ejemplos de constituciones modernas escritas, donde se sancionaban unos derechos naturales por encima de cualquier ley o gobernante, protegiéndolos así de cualquier abuso de poder, viniese éste de donde viniese. De ese modo, en el republicanismo calvinista "el pueblo se presenta como legislador en la medida que elige a un magistrado que tiene como misión compatibilizar los intereses plurales de sus representados" 32 .

\subsection{Causas del declive puritano}

Habiendo dotado al resto de las colonias de un ejemplo de constitución interna y habiendo moldeado el carácter e historia de toda Nueva Inglaterra, ¿cómo es que el puritanismo, un siglo más tarde, no fue la principal fuente del pensamiento revolucionario? Para explicarlo se pueden aducir cuatro razones históricas principales, la primera, ya señalada, radicaba en la localización concreta de los puritanos en Nueva Inglaterra. Por supuesto que hubo puritanos también en las áreas de Chesapeake o el Caribe, como demuestra Alexander Whitaker, conocido como el "Apóstol de Virginia" 33 , pero en ellas primaban los intereses económicos o militares sobre los confesionales.

En segundo lugar, a partir de mediados del siglo XVII se produjeron los primeros intentos de racionalización del Imperio Británico americano, proceso que se agudizó tras la Restauración. Nueva Inglaterra no fue ajena y Massachusetts vio anulada su carta en 1684 por Jaime II, pasando a control de la Corona bajo el breve dominio de Nueva Inglaterra, que incluía además New Hampshire, Rhode Island, Plymouth, Connecticut, New Jersey y New York, donde quedaron abolidas las asambleas locales, siendo administrada en su conjunto por un gobernador nombrado por la Corona $^{34}$. En 1691, superada ya la Revolución Gloriosa, Massachusetts se convirtió definitivamente en colonia real con un gobernador nombrado por Londres y el respeto de la libertad de culto asegurado, mientras que el resto corrió mejor suerte al ser de nuevo respetados sus anteriores ordenamientos ${ }^{35}$.

En estrecha relación con el aumento del control británico, en tercer lugar se encuentra la constante secularización de las colonias norteamericanas. A pesar de que el pensamiento de la mayoría de los colonos continuaba dominado por el universo religioso, el aumento de las preocupaciones materiales y el individualismo que ello implicaba fueron socavando el dominio que los ministros puritanos venían ejercien-

\footnotetext{
G. Jellinek, op. cit., p. 105.

A. Rivera García, Republicanismo calvinista, Murcia, DM, 1999, p. 117.

D. Steinmetz, op. cit., p. 5.

C. Ubbelohde, op. cit., p. 31.

S. Sarson, op. cit., p. 142.
} 
do sobre la sociedad. En su lugar, mercaderes y abogados fueron ocupando los primeros puestos de unas élites que habían abandonado el ideal comunitario de los primeros años de colonización, pareciéndose así cada vez más al resto de colonias al sur del Hudson ${ }^{36}$. El paso de una economía de subsistencia a otra exportadora, para 1700 el comercio con Norteamérica representaba ya una sexta parte del comercio total británico, fue sin duda un acicate para la secularización de unas poblaciones dominadas hasta entonces por el ideal religioso.

Por último, y como precursor político de todos los cambios que hemos señalado, cabe destacar la imparable democratización que se vivía en el seno de las colonias puritanas. Si Roger Williams había unido democratización política a libertad religiosa, en la propia Massachusetts la rigidez puritana pronto hubo de enfrentar las demandas populares de una mayor apertura política. En 1641 su Cuerpo de Libertades abolió todo tipo de privilegios feudales, y salvo en religión, instauró la igualdad ciudadana ante la ley. La lucha contra el aristocratismo puritano continuó y en 1644 se creó una segunda cámara legislativa, compuesta por representantes locales, con dos diputados por cada pueblo, cuyas reivindicaciones frente a la cámara inicial de los asistentes consistían en la extensión de la ciudadanía a todo hombre libre y el control absoluto de los magistrados por la asamblea elegida mediante sufragio universal. La reacción puritana ante dicho radicalismo democrático consistió en presentar un constitucionalismo republicano que nada pudo hacer ante la pérdida de peso político sufrida por la oligarquía eclesiástica, es más, tras la Restauración, su falta de apoyo público y la concesión de derechos políticos a todo hombre libre provocaron que el aristocratismo puritano de las primeras décadas cediera paso a la inevitable democratización de su sociedad ${ }^{37}$.

A todas estas razones históricas habría que sumar una última cuestión dogmática, nada desdeñable teniendo en cuenta el carácter rigorista de los puritanos arribados al litoral Atlántico norteamericano. Habiendo trastocado la Reforma no solo el orden religioso, sino también el político en media Europa, provocando la reacción del Papado y de las casas reales leales a él, es lógico que sus precursores se preocupasen por principios políticos como el derecho a la resistencia. Así, Calvino, defendiendo el origen divino de toda autoridad, eclesial y laica, rechazaba que cualquier ciudadano tuviese el derecho a resistir a sus superiores, y menos de forma violenta. La rebelión del pueblo quedaba descartada bajo una resistencia pasiva consistente en la observancia de sus prácticas, reservando el derecho a la resistencia a su noción de libertador providencial y, en especial, a las autoridades legítimamente constituidas (como la reunión de los tres estados en Francia) ${ }^{38}$, pues si era la voluntad divina "reges regnis praeficere, liberis civitatibus senatores aut decuriones, quoscunque locis praefecerit in quibus degimus, nostrum est iis nos morigeros ac obedientes praestare" 39 . De ese modo, "only activity by properly constituted authorities was justifiable" ${ }^{\text {"40 }}$.

$36 \quad$ Ibidem, p. 146.

37 H. L. Osgood, op. cit., p. 27.

38 E. Doumergue, "Los orígenes históricos de la Declaración de Derechos del Hombre y del Ciudadano", en J. Amuchastegui (ed.), op. cit., pp. 167-225, p. 171.

39 J. Calvino, op. cit., p. 562, si bien al mismo tiempo aseguraba que "quin etiam uc summa diligentia intenti magistratus esse debent, ne qua in parte libertatem, cuius praesides sunt constituti, minui, nedum violari patiantur. Si in eo sunt segniores et parum solliciti, perfidi sunt in officio et patriae suae proditores", Ibidem, p. 561.

40 H. Höpfl, The Christian Polity of John Calvin, Cambridge, Cambridge University Press, 1985, p. 48. 
En todo caso, los malos gobernantes eran concebidos por Calvino como un castigo divino, que solo cuando faltasen también a la ley divina podrían ser depuestos. Con tales contradicciones en su pensamiento, Calvino abrió inconscientemente la puerta a la legitimación total del derecho a la resistencia, de hecho, una década después de su muerte sus discípulos habían modificado o rechazado por entero su doctrina de obediencia política. Teodoro Beza, su sucesor al frente del movimiento calvinista, rebajó el umbral de la resistencia pasiva al indicar en su trabajo más significativo al respecto, De iure magistratuum in subditos, que el pueblo podía oponerse al tirano que violase los derechos humanos y divinos, al convertirse así en enemigo del Estado, eso sí, antes debían cumplirse tres condiciones, a saber: que la resistencia se realizase de forma correcta, sin ofender a Dios y contra verdaderos tiranos. De no ser así, el pueblo estaba obligado a soportar las injusticias de aquellos ${ }^{41}$.

Como se observa, para los primeros calvinistas la resistencia era entendida como una tarea religiosa, no como un deber moral, y por tanto, difícilmente podía convertirse en un derecho político. Quienes sí dieron ese paso fueron los Hugonotes en Francia, al unir la teoría de la resistencia calvinista con las teorías constitucionalistas a favor de un gobierno limitado y menos absoluto, todo ello bajo el influjo humanista que les condujo a buscar en la tradición medieval la justificación de unas leyes y costumbres propias frente a los novedosos esfuerzos absolutistas ${ }^{42}$. Dicha teoría pasó primeramente a Holanda y de ahí a Gran Bretaña.

En Inglaterra, el acceso de María Tudor al trono en 1553 supuso un grave perjuicio a los reformados, unos trescientos de los cuales fueron quemados por herejes, de ahí que el discurso reformado en la isla fuese, desde un principio, más radical que en el continente ${ }^{43}$. Los reformistas que, como John Knox o Cristopher Goodman, llevaron el calvinismo a Escocia desde la misma Ginebra, privatizaron e individualizaron la doctrina recibida del propio Calvino. Para Goodman y John Ponet, Obispo de Winchester, cada magistrado tendría asignada una función, con lo que los reyes tendrían asimismo limitado su poder, quedando así justificada la resistencia ante el gobernante que se extralimitase en el ejercicio de sus funciones ${ }^{44}$, además, negaban que los tiranos hubiesen recibido su poder de Dios, por lo que dicha resistencia devenía legítima, extendiendo así al pueblo mismo la capacidad de resistir reservada hasta el momento a los magistrados ${ }^{45}$. George Buchanan, influido por los anteriores, y como autor de los Diálogos que se convirtieron en el manual político del calvinismo escocés, sostuvo la necesidad de confinar al rey en las prisiones de la $1 \mathrm{ley}^{46}$, pues rechazaba todo absolutismo por contrario al bien popular, único fin al que debían dedicarse los magistrados. Por tanto, la resistencia estaba justificada cuando el magistrado, convertido en tirano, rompiese con el pacto e infringiese las leyes ${ }^{47}$. Con ello,

${ }_{41}$ M. Llanos, "El derecho de resistencia en el pensamiento político de Teodoro Beza", en Revista de Estudios Histórico-Jurídicos XXV, 2003, pp. 483-504, p. 501. La reiteración calvinista en la resistencia llevada a cabo debidamente, es decir, a través de los representantes del pueblo y no por el pueblo mismo, también la encontramos en el texto por excelencia del calvinismo francés, el Vindicae contra tyranos, atribuido a Duplessis-Morney, E. Doumergue, op. cit., p. 186.

42 Q. Skinner, The Foundations of Modern political Thought, Vol. 2, The Age of Reformation, Cambridge, Cambridge University Press, 1978, p. 268.

$43 \quad$ Ibidem, p. 221.

44 Ibidem, p. 223.

45 Ibidem, p. 234.

46 E. Doumergue, op. cit., p. 194.

47 H. L. Osgood, op. cit., p. 12. 
Buchanan se convirtió en el más radical de los reformadores ingleses, al desarrollar una teoría completamente secular al negar la existencia de un pacto del pueblo con Dios, siendo el pueblo mismo el que elige ser gobernado a través de sus representantes, no perdiendo nunca su soberanía y, por ello, estando capacitado a deponer en todo momento al monarca que no cumpla con el pacto por el cual fue investido ${ }^{48}$.

El propio Calvino quedó horrorizado ante la defensa de la revuelta popular defendida por Ponet, Knox y Goodman, pues entendía más acorde con sus enseñanzas la legalidad esgrimida por los Hugonotes en Francia, quienes llevados por la necesidad de ampliar la base de sus apoyos, al encontrarse en clara minoría, se mantuvieron en los límites constitucionales y defensivos como mejor estrategia para mantener la precaria tolerancia de la que disfrutaban en Francia ${ }^{49}$. Las masacres de la Noche de San Bartolomé en 1572, ahogaron toda esperanza de dicha vía constitucional, aunque François Hotman continuara defendiéndola en su Francogallia ${ }^{50}$.

En resumen, al hacer del derecho a la resistencia un asunto teológico, más que político, el puritanismo fue incapaz de ofrecer a los colonos del siglo XVIII una justificación a sus reivindicaciones revolucionarias. Además, los cambios producimos en un siglo de colonización sobre la sociedad norteamericana, y que como se ha señalado, tendían a la secularización y democratización de su sistema sociopolítico, condujeron a los rebeldes a buscar en otras fuentes los argumentos principales de su discurso revolucionario. En cualquier caso, la herencia puritana se dejaría sentir en dos aspectos fundamentales de la revolución estadounidense, el carácter democrático de su revuelta y el radicalismo constitucional que dominó los primeros años de Independencia.

\section{Periodo revolucionario y constitucional: Similitudes entre puritanismo y republicanismo clásico}

La exigente teoría de la resistencia calvinista, con sus múltiples requisitos para ser esgrimida, contrasta con lo que se ha calificado como la revolución con menos motivos de la historia, es más, hay autores que, como Moore, niegan el carácter revolucionario de la Independencia de Estados Unidos ${ }^{51}$. Lo cierto es que en la América Británica, a diferencia de lo que ocurriría más tarde en Francia, hubo un ejercicio controlado de libertad que evitó caer en el despotismo para luchar contra la tiranía. Si eso fue así, en parte se debió a la herencia puritana, pero el mérito se ha de conceder en gran medida al republicanismo clásico, auténtico catalizador de las distintas fuentes que informaron el pensamiento revolucionario de los colonos de la América Británica $^{52}$. Como señala Wood, con anterioridad a la Independencia, el liberalismo no fue concebido en dichas colonias como una ideología, a diferencia del republicanismo clásico, sino como la voz de realidades concretas como la competitividad

48 Q. Skinner, op. cit., p. 344.

49 Ibidem, p. 306.

50 Ibidem, p. 314, donde Hotman abogaba por una monarquía electiva y limitada por una constitución mixta y principalmente a través de la recuperación del poder fiscalizador de ciertos magistrados, función que en su obra tardía Calvino había asignado a los éforos.

51 B. Moore, Los orígenes sociales de la dictadura y de la democracia, Barcelona, Ariel, 2015, p. 120.

52 B. Bailyn, The Ideological Origins of the American Revolution, Cambridge, Harvard University Press, 1967, p. 46. 
humana, el interés propio o la ausencia de estados sociales en América, y solo más tarde, cuando el proceso de democratización se impuso al espíritu aristocrático inicial, el liberalismo pudo convertirse en la ideología dominante en Estados Unidos ${ }^{53}$.

El republicanismo clásico era más acorde al temperamento y realidad de las colonias de mediados de siglo XVIII que el rigorismo puritano de inicios de la colonización, que se encontraba además asediado por el carácter democrático del primer Gran Despertar iniciado en la década de 1730, y que, al apelar a la individualidad, minó la disciplina de culto y avivó el pluralismo religioso ${ }^{54}$. Gracias al republicanismo clásico, los revolucionarios norteamericanos pudieron crear un relato que dio sentido a sus reivindicaciones no con base teológica, sino política, y por tanto, sin necesidad de recurrir a la Iglesia y a la obediencia de la ley divina ${ }^{55}$.

Como señala Pocock, la Revolución y Constitución estadounidenses pueden entenderse como el último acto del Renacimiento y Humanismo cívicos, tras su auge en Italia y su recepción en Inglaterra ${ }^{56}$. Si el puritanismo no pudo ofrecer un discurso legitimador al descontento de muchos colonos, se debió a la transformación de su pensamiento, que requería un nuevo marco conceptual desde el cual justificar no solo su ruptura con la metrópoli, sino también un nuevo sistema americano ${ }^{57}$.

Pero si el republicanismo clásico pudo convertirse en el catalizador del pensamiento revolucionario fue gracias a que compartía numerosos elementos con el puritanismo que marcó los primeros años de colonización, y con ello el nacimiento de un modelo genuinamente americano. El primero de ellos sería el estudio de los autores clásicos grecolatinos. El mismo Calvino estudió el pensamiento humanista desde su llegada a París en 1523, primero bajo el magisterio del sacerdote humanista Mathurin Cordier y más tarde en el colegio dirigido por Noel Beda, y tras obtener el grado de maestro en artes y convertirse en doctor en leyes en Orleans, escribió con 23 años su primera obra, un comentario sobre De Clementia de Séneca. Por esa misma época se produjo en Calvino su conversión definitiva a los postulados reformistas, bajo la influencia de Melchior Wolmar, humanista favorable al movimiento de la Reforma ${ }^{58}$. Así, para Höpfl, en su transición del escolasticismo a la reforma, el humanismo jugó en Calvino un papel crucial como mediador indispensable ${ }^{59}$.

En su tránsito a Escocia, el calvinismo tampoco perdió su relación con los clásicos, así, Buchanan, influido por ellos, y en particular por Aristóteles, llevaría un

53 G. S. Wood, "Ideology and the Origins of Liberal America", en The William and Mary Quarterly 44, 1987, pp. 628-640, aquí en p. 636.

54 G. S. Wood, "Rhetoric and Reality in the American Revolution", en The William and Mary Quarterly 23, 1966, pp. 3-32 aquí en 15.

55 J. G. A. Pocock, El momento maquiavélico. El pensamiento político florentino y la tradición republicana atlántica, Madrid, Editorial Tecnos, 2002, p. 42.

$56 \quad$ Ibidem, p. 563.

57 En palabras de John Adams "what do We mean by the Revolution? The War? That was no part of the Revolution. It was only an Effect and Consequence of it. The Revolution was in the Minds of the People, and this was effected, from 1760 to 1775", carta de John Adams a Thomas Jefferson (24 de septiembre de 1821), recuperado de Internet (http://founders.archives.gov/documents/Adams/99-02-02-7548), y de Alexander Hamilton "we are laboring hard to establish in this country principles more and more national and free from all foreign ingredients-so that we may be neither "Greeks nor Trojans" but truly Americans", Carta de Alexander Hamilton a Rufus King (16 de septiembre de 1796) recuperado de Internet (http://founders.archives.gov/documents/Hamilton/01-20-02-0285).

58 Th. H. Dyer, Life of John Calvin, London, Bradbury \& Evans, 1850, p. 9 y Th. Beza, The Life of John Calvin, Philadelphia, WM. S. Martien, 1836, p. 5.

59 H. Höpfl, op. cit., p. 226. 
paso más el derecho de resistencia esbozado por Calvino. Ya en Inglaterra, el mejor ejemplo de puritanismo renacentista se encuentra en John Milton, con su mezcla de saber antiguo y voluntad de progreso ${ }^{60}$.

Por tanto, la tradición clásica aportó al puritanismo y al republicanismo clásico un fondo de conocimiento común, que en los colonos sirvió para que la transición del primero al segundo sucediese de forma natural. Como señala Richard, los clásicos brindaron a los Padres Fundadores, con su influencia formativa, importantes herramientas intelectuales como la teoría del gobierno mixto, una concepción de la naturaleza humana basada en la virtud y un sentido, una identidad y un propósito a sus vidas fuera del ámbito religioso ${ }^{61}$. Gracias a los clásicos, se da la paradoja de que la revolución de Estados Unidos estuviese alimentada por la tradición ${ }^{62}$, los revolucionarios pudieron así remitirse tanto a la Biblia como a la República, a Calvino como a Aristóteles, sin entrar en contradicción por ello.

Debido a esa referencia constante a los clásicos, el puritanismo y el republicanismo clásico de los Padres Fundadores comparten un segundo rasgo esencial de su pensamiento, un marcado aristocratismo que en definitiva relegaría a ambos a un segundo plano. Calvino, en el capítulo dedicado a la potestad civil de su Institución, y siguiendo la tipología creada por Polibio, afirmaba que no podía hablarse de una forma de gobierno mejor que otra, pues todo depende de las circunstancias ya que la monarquía sería más proclive a la tiranía al depender de uno solo, pero la aristocracia tampoco estaría libre de peligros, "non-multo difficilior ab optimatum potestate in paucorum factionem" 63 , igual que sucedería con la democracia al abrir la puerta de la sedición y el faccionalismo. En todo caso, "equidem si in se considerentur tres illae, quas ponunt philosophi, regiminis formae, minime negaverim vel aristocratiam, vel temperatum ex ipsa et politia statum, aliis omnibus longe excellere" ${ }^{\text {"64 }}$.

La predilección de Calvino por el régimen aristocrático data de 1542, cuando estaba convencido de "an aristocratic arrangement, where the ecclesiastical collectivity is governed by an aristicracy of merit" 65 , y un año después proclamaba ya claramente la superioridad sobre el resto de sistemas políticos de la aristocracia, ya fuera en su forma pura o bajo un gobierno mixto ${ }^{66}$. Para Calvino, "l'aristocratie serait la forme de gouvernement la plus tolérable à la condition que ses membres puissent $s$ 'aider en se contrôlât et se censurant réciproquement, pour conjurer le danger de voir l'aristocratie dégénérer en oligarchie" 67.

Ya en Inglaterra, los humanistas que asistieron a la victoria del New Model Army y la posterior decapitación de Carlos I en 1649, aprovecharon el desorden político para publicitar su ideario republicano y presentar alternativas a la monarquía. Para la mayoría de dichos autores, la reforma política era el primer paso de la reforma

\footnotetext{
R. H. Bainton, op. cit., p. 185.

61 C. Richard, The Founders and the Classics. Greece, Rome, and the American Enlightenment, Cambridge, Harvard University Press, 1995, p. 8.

$62 \quad$ Ibidem, p. 232.

63 J. Calvino, op. cit., p. 561.

${ }^{64}$ Ibidem. Como indica Larson, "his preference for a mixed government with aristocratic and democratic elements reflect his fear of autocracy", en M. L. Larson, Calvin's Doctrine of the State, Eugene, Wipf \& Stock, 2009 , p. xiv.

65 H. Höpfl, op. cit., p. 97.

66 Ibidem, p. 153.

${ }_{67}$ M. Trunchetti, "Contribution de Calvin et de le calvinisme à la naissance de la démocratie moderne", en M. E. Hirzel y M. Sallmann, op. cit., p. 300.
} 
social, por lo que se centraron en describir lo que consideraban un buen gobierno, basado en la virtud, es decir, justo, eficiente y respetuoso de la libertad de la comunidad, y tan solo los más radicales abogaban ya por extender dicha virtud al conjunto de la sociedad, obligando así a impulsar su participación política, entendida como expresión de su libertad ${ }^{68}$.

Dentro de la corriente mayoritaria y más moderada, sus tres grandes representantes, John Milton, James Harrington y Algernon Sidney, añadieron al pensamiento republicano elementos ajenos a él hasta el momento como las ideas del contrato social, de la resistencia o de los derechos naturales, que unidos a un profundo sentimiento religioso, acabaron por producir un republicanismo marcadamente aristocrático ${ }^{69}$.

Pero la Revolución Gloriosa fue de inspiración whig, no republicana, dominada por una nueva generación de pensadores como John Locke o Halifax, primer utilitarista en la historia del pensamiento político inglés, lo que condujo al fin del partido republicano a finales del siglo XVII, cuyos principios serían recuperados en las colonias británicas de Norteamérica ${ }^{70}$. Pese a la inexistencia de un pasado feudal y de claras divisiones sociales, el aristocratismo también atrajo en un principio a la mayoría de líderes revolucionarios, si bien transformado en su esencia, pues de una aristocracia hereditaria se pasó a reivindicar una de origen natural, integrada por los más sabios y virtuosos de la sociedad ${ }^{71}$. Así, el máximo representante del republicanismo en las colonias, John Adams, describió dicha aristocracia natural como "a body of men which contains the greatest collection of virtues and abilities in a free government; is the brightest ornament and glory of the nation; and may always be made the greatest blessing of society, if it be judiciously managed in the constitution"72. James Madison, que pronto rompería con la corriente Federalista, no escaparía al predicamento aristocrático, y criticando los Artículos de la Confederación, aseveraría que

An auxiliary desideratum for the melioration of the Republic form is such a process of elections as will most certainly extract from the mass of the Society the purest and noblest characters which it contains; such as will at once feel most strongly the proper motives to pursue the end of their appointment, and be most capable to devise the proper means attaining it ${ }^{73}$.

68 R. Ruiz, La tradición republicana, Madrid, Editorial Dykinson, 2006, p. 165.

${ }_{69}$ Ibidem, p.178. Milton evolucionó de un aristocratismo espiritual y cristiano, donde las élites estaban formadas por los poseedores de tales virtudes, a un aristocratismo más democrático donde la virtud debía fomentarse desde el gobierno, conducido, eso sí, por los más sabios y virtuosos. Aunque Milton creía en el concepto de soberanía popular, nunca tuvo fe en el gobierno representativo, G. P. Gooch, English Democratic Ideas in the Seventeenth Century, New York, Harper Torchbooks, 1959, p. 208. En Harrington encontramos el mismo aristocratismo, si bien bajo una noción abierta donde cualquiera podía ascender a las élites a través de la educación y la riqueza. Por último, el republicanismo de Sidney no implicaba la democratización del sistema, tan solo el consentimiento y algún tipo de acción parlamentaria en un gobierno mixto conducido por los mejores, pues lo esencial era mantener controlado el poder arbitrario inherente a todo sistema, Ibidem, p. 285.

70 Ibidem, p. 299.

71 J. G. A. Pocock, op. cit., p. 625.

72 J. Adams, Defence of the Constitutions of Government of the United States of America, Philadelphia, Hall and Sellers, 1787 , p. 116.

73 R. D. Brown (ed.), Major Problems in the Era of the American Revolution 1760-1791, Lexington, D. C. Heath and Company, 1992, p. 422. 
Incluso Thomas Jefferson, el más radical y populista de los Padres Fundadores, reconocería al mismo John Adams que "there is a natural aristocracy among men. The grounds of this are virtue and talents" "74, es más, "the natural aristocracy I consider as the most precious gift of nature, for the instruction, the trust, and government of society" 75 , por consiguiente, "that form of government is the best, which provides the most effectually for a pure selection of these natural aristoi into the offices of government?"76.

El cariz aristocrático del republicanismo nos conduce a la tercera coincidencia con el puritanismo. Para el humanismo renacentista, la virtud se convirtió en la fuente de legitimidad del nuevo orden, en sustitución de la costumbre y la gracia (Divina), de modo que, como indica Pocock, en el siglo XV, la idea de hacer efectiva una comunidad cívica era un proyecto muy cercano al puritano de erigir en la tierra una comunidad santa ${ }^{77}$. Respecto a la libertad, para Calvino "videmus in summa, quorsum haec tendat libertas, nempe ut Dei donis nullo conscientiae scrupulo, nulla animi perturbatione utamur, in quem usum nobis ab ipso data sunt"78, mientras que para los autores republicanos la libertad consistía en practicar la virtud cívica, es decir, en subordinar los intereses privados a la consecución del bien común, pues solo acatando la ley por todos aceptada se podía ser libre, imagen que se convirtió para los revolucionarios norteamericanos en el objetivo de su independencia ${ }^{79}$. Por tanto, el republicanismo demandaba una sociedad de extraordinario carácter, cuya exigencia cívica tanto recuerda y concuerda con la práctica puritana, no en vano, como señala Schneider, el congregacionalismo "was a social reform movement with a complete ideology" ", tal y como fue después el republicanismo.

Para el teólogo y misionero estadounidense Jonathan Edwards, según se recoge en su afamado comentario A Dissertation Concerning the Nature of True Virtue, publicado póstumamente en 1765, "true virtue ... is that consent, propensity and union of heart to being in general, that is immediately exercised in a general good will" Benjamin Franklin, quien a pesar de crecer en un ambiente puritano desarrollaría una noción secular y utilitaria de esa misma benevolencia, resumiría las virtudes esenciales en templanza, silencio, orden, resolución, frugalidad, industria, sinceridad, justicia, moderación, limpieza, tranquilidad, castidad y humildad ${ }^{82}$. Lo esencial en ambas visiones es la naturaleza asequible de dicha virtud, pues al contrario de la visión pesimista desarrollada por San Agustín, los puritanos y los revolucionarios estadounidenses creían en la perfectibilidad del hombre, compartiendo el ideal de excelencia universal del Renacimiento, y que tan bien se refleja en la obra de Petrar-

\footnotetext{
74 A. Koch, The American Enlightenment. The Shaping of the American Experiment and a Free Society, New York, George Braziller, 1965, p. 356.

75 Ibidem.

76 Ibidem.

77 J. G. A. Pocock, op. cit., p. 194.

78 J. Calvino, op. cit., p. 321.

79 G. S Wood, The Creation of the American Republic 1776-1787, New York, W. W. Norton \& Company, 1993, p. 53.

80 H. W. Schneider, A History of American Philosophy, New York, Columbia University Press, 1946, p. 3. De hecho, para Calvino, la tarea de los magistrados debía consistir en "to see to the piety and virtue of the citizenry by means of laws and directives", en H. Hópfl, op. cit., p. 189.

81 J. Edwards, A Dissertation Concerning the Nature of True Virtue, 1765, recuperado de Internet (http://www. apuritansmind.com/puritan-favorites/jonathan-edwards/theological/the-nature-of-true-virtue/)

82 A. Koch, op. cit., p. 64.
} 
ca, para quien alcanzar la virtud no solo era una posibilidad, sino un deber ${ }^{83}$. Tal relación entre puritanismo y republicanismo debida al estudio y admiración del mundo clásico no es sorprendente, como indica Schneider, "the sources of Congregational Puritanism take us back to Renaissance Platonism" "84, en especial del Hugonote Peter Ramus (Pierre de la Ramée), quien tanta influencia tendría en Nueva Inglaterra, con seguidores de la talla de Thomas Hooker, Samuel Johnson o el mismo Jonathan Edwards ${ }^{85}$,

No es extraño, por tanto, que en las colonias republicanismo y puritanismo se diesen la mano para luchar por una independencia que ambos consideraban como la única salida a la corrupción importada desde Londres ${ }^{86}$. Además, y como consecuencia de un concepto de virtud orientado al conjunto de la sociedad, en ambas concepciones la comunidad se imponía al individuo, en la puritana a través de la Iglesia y en la republicana a través de la república, donde su teoría del gobierno mixto tan bien casaba con la democracia congregacionalista de los primeros colonos de la América Británica. Así, los diferentes ordenamientos de las colonias, convertidos tras la Revolución en constituciones, supusieron el reconocimiento de los derechos del hombre frente a los derechos del Estado, lo que marcaría el tránsito del Estado antiguo al moderno, de la mano de unas Declaraciones de Derechos que convirtieron la filosofía de la libertad en legislación aplicable a la vida real ${ }^{87}$.

De hecho, como señala Wood, se puede establecer una relación recíproca entre constitución mixta y espíritu virtuoso popular, a través de un fervor idealista del poder regenerador del gobierno republicano, pues para los Padres Fundadores la libertad sin virtud carecía de valor ${ }^{88}$. En todo caso, para los creadores de la Constitución de 1776, el republicanismo había que diferenciarlo de la democracia, de la que recelaban si no era templada a través del gobierno mixto, por el contrario, los radicales como Thomas Paine y los redactores de la constitución de Pennsylvania, la más extrema de todas al instaurar un régimen unicameral bajo estricto control popular, abogaban por no cercenar el libre ejercicio del poder político del pueblo, rechazando cualquier atisbo de aristocratismo ${ }^{89}$.

83 Q. Skinner, The Foundations of Modern political Thought, Vol. 1 The Renaissance, Cambridge, Cambridge University Press, 1978, p. 93.

84 H. W. Schneider, op. cit., p. 5.

85 Con William Ames habiendo servido de "puente entre el ramismo y el calvinismo que se gestaron en Francia y la mentalidad que importaron a la costa este de los futuros Estados Unidos los primeros colonos", en L. Adrián Lara, Dialéctica y calvinismo en la teoría politica contemporánea, Tesis Doctoral, UCM 2012, p. 324.

86 G. S Wood, The Creation..., op. cit., p. 118.

87 G. Jellinek, op. cit., p. 156.

88 G. S Wood, The Creation..., op. cit., p. 119.

89 Ibidem, p. 222. Los republicanos norteamericanos coincidían así con Calvino, que viendo deseable algún tipo de participación popular, lo hizo siempre desde la premisa de que fuera controlada y gobernada para defender a la comunidad del abuso ciudadano de su libertad electoral. Para Calvino, lo principal en su pensamiento político fue siempre aclarar la autorización de las personas destinadas a puestos de magistratura, muy por encima del papel del pueblo en dicha selección. H. Höpfl, op. cit., p. 160. 


\section{Incidencia del puritanismo y republicanismo en el conservadurismo de Estados Unidos}

La cuestión de la virtud fue esencial para el constitucionalismo estadounidense, como señaló Samuel Osgood, quien hasta el momento se había opuesto al plan Federalista, el patriotismo y la virtud "are no match in this country for dishonesty and intrigue. Americans have no more virtue than other people"90. Para lidiar con semejante imperfección se presentaron tres vías principales, la primera, continuar sin ningún cambio pues, como se recogía en el Newport Herald, "there was virtue enough in the people under so mild a constitution" "91, la segunda, la reforma interna a través de la creación de la Esparta Cristiana soñada por Samuel Adams, y que tuvo en las Asambleas del Té su materialización organizativa más señera, y en último lugar, la reforma de sistema político, con la superación de los Artículos de la Confederación a través de un nuevo orden constitucional capaz de trascender esa falta de virtud del pueblo norteamericano. Esa tercera vía fue la defendida por los Federalistas, que preocupados por la deriva radical de las legislaturas estatales, reclamaban un gobierno central fuerte que dotase de cierta homogeneidad al sistema político norteamericano, a la vez que permitiese, esta vez sí, la elección de los más virtuosos para los puestos de poder. Ese esquema de un gobierno federal fuerte fue tan revolucionario en sí mismo como lo había sido en su día el alzamiento contra la Corona Británica ${ }^{92}$, pero hasta ahí llegó la modernidad Federalista, pues al tratar de salvar la Revolución de sí misma, recurrieron al republicanismo más conservador y elitista, cuya estrecha noción de virtud acabaría imponiendo un sistema tan disfuncional como el existente bajo los Artículos de la Confederación. De hecho, el esfuerzo Federalista cabe interpretarlo como un ajuste del sistema político a un pueblo no virtuoso, moderando los aspectos negativos de sus vicios ${ }^{93}$. Con ello, los Federalistas convirtieron al republicanismo en una ideología de control de la estratificación social, para impedir que los faltos de preparación llegasen al poder a través de mecanismos democráticos, cuyo fin, bien al contrario, debía ser la creación de una élite gobernante del talento y la virtud $^{94}$.

El ideario Federalista se plasmó íntegramente en la Constitución de 1787 que, como clara reminiscencia del pacto puritano, se concibió como un texto cuasisagrado, pues como ley de leyes, debía estar por encima de toda institución por ella sancionada, incluso la Legislativa ${ }^{95}$. De lo que se trataba era de preservar la libertad frente al Estado, pero también de protegerla del pueblo mismo, de sus excesos e imperfecciones. Ya en 1645 John Winthrop, como Gobernador de Massachusetts, había definido la libertad civil como "the proper end and object of authority and cannot subsist without it; and it is a liberty to that only which is good, just, and honest"'96, pues "this liberty is maintained and exercised in a way of subjection to authority; it

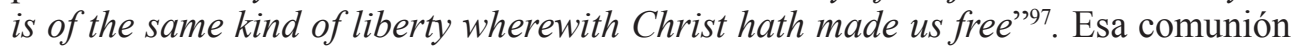

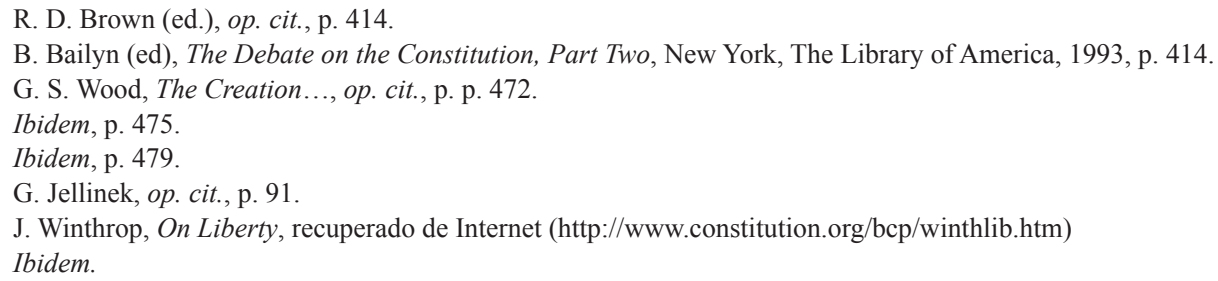


de elementos teológicos y políticos ha hecho ver en autores como Schneider la teoría del pacto de la Iglesia como el aspecto eclesiástico de la teoría del contrato social, especialmente adaptada a unas clases medias y círculos mercantiles que formaban la vanguardia de esa corriente histórica que forzó el tránsito de la sociedad feudal a la moderna ${ }^{98}$.

Por consiguiente, con sus principios de soberanía popular y representación política, las comunidades calvinistas sentaron las bases para la puesta en práctica del Estado laico, tal y como había sido ensayado por primera vez con Roger Williams ${ }^{99}$. No en vano, como producto de la Reforma, sin el republicanismo calvinista no se entendería la obra política de la mayoría de teóricos del republicanismo ${ }^{100}$. Es más, en el caso particular de Estados Unidos, "without some understanding of this intense pristine idealism of New England, it is hard to understand the subsequent development of American character...the general principle that life should be governed by ideal aspirations... became, in New England, itself customary"101. Pero, como señala Schneider, "the Puritan virtues... were not traditionally Christian. This divorce from the Christian moral tradition...is at the heart of the contrast between the Yankee and the Christian"102, y, como se ha tratado de demostrar a lo largo de estas líneas, es el motivo principal del conservadurismo republicano que caracterizó los periodos revolucionario y constitucional. Sin dicho conservadurismo Estados Unidos sería más parecido a Europa, él es la base de su excepcionalismo, y es lo que, en pleno siglo XXI, refuerza su vigencia. De ahí que en todo periodo en que el liberalismo es cuestionado, como sucedió a finales del siglo XIX y ocurre en la actualidad, los principios y valores más conservadores, procedentes de las tradiciones puritana y republicana, sean esgrimidos para la reforma de un sistema que se percibe corrompido por sus excesos, confirmando el sustrato conservador sobre el que se sostiene la corteza liberal del carácter nacional estadounidense.

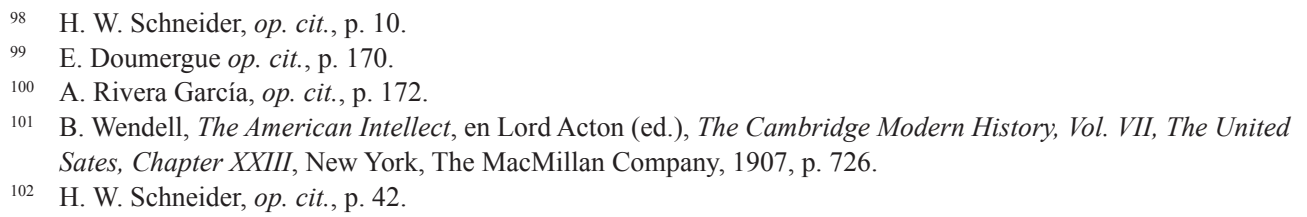

